MATEC Web of Conferences 51, 02001 (2016)

DOI: $10.1051 /$ matecconf/20165102001

(C) Owned by the authors, published by EDP Sciences, 2016

\title{
A Study on Wind-Induced Smoke Extraction Systems for Building Fires
}

\author{
ShengBang $\mathrm{LI}^{1}$, ChungHwei SU ${ }^{1, a}$, Kuang-Chung TSAI ${ }^{1}$ \\ ${ }^{1}$ Department of Safety, Health and Environmental Engineering, National Kaohsiung First University of Science and \\ Technology, 82445 Kaohsiung City, Taiwan
}

\begin{abstract}
Since smoke is one of the lethal factors at the scene of a fire, the effectiveness of a smoke control system is of great importance. Buildings are likely to be influenced by natural winds, so the effectiveness of a natural smoke extraction system is often questioned. This study discusses the feasibility of using the Venturi principle to improve a natural smoke extraction system for buildings under the effect of wind. The findings show that side smoke extraction is likely to be influenced by external air flow. Smoke extraction can clearly be improved if a negative pressure zone is formed outside the smoke vent.
\end{abstract}

\section{Research motives and Purposes}

\subsection{Hazards of smoke at the scene of a fire}

Populations are concentrated in cities in various countries where there is rapid growth in technology and the economy. In past years, as population densities increased, more accidental fires have caused casualties, increasing attention to the subject of building fire safety [1, 2].

Smoke at the scene of a fire can be lethal. The hazards of smoke include high temperature, toxicity and obscuration. The first two hazards can cause immediate death. The last hazard can negatively affect the evacuation of people and the work of rescue personnel [3]. "Smoke" is defined by the National Fire Protection Association (NFPA) as airborne solids and liquid particulates and gases evolved when a material undergoes pyrolysis or combustion, together with the quantity of air that is entrained or otherwise mixed into the mass" [4]. How to effectively control and remove the smoke at the scene of a fire is an important research subject.

\subsection{Flow and control of smoke}

At the scene of a fire, smoke moves with the air flow. The flow of the smoke can be influenced by a natural driving force and a forced driving force. The former one includes the stack effect, buoyancy, expansion and natural wind. The latter one includes an HVAC System and elevator piston effect [5].

A smoke control system can clearly enhance the safety of the residents in the buildings. When people are being evacuated, the smoke control system keeps the escape routes free from smoke that

\footnotetext{
${ }^{a}$ Corresponding author : such@nkfust.edu.tw, georgesu2000@gmail.com
} 
obscures vision. These smokeless admission passages are created for the fire fighters to increase their rescue efficiency.

The control of smoke can be divided into "natural" and "forced" types. The natural smoke control system uses the elements inside the building to confine the flow of smoke to a region. This system is free of power consuming equipment. There is no need for emergency power when a fire happens [6].

\subsection{Natural smoke extraction system under the effect of natural winds}

Some scholars have proposed using the ventilation tower of a Venturi-shaped roof to increase the air rate and ventilation rate in the buildings. Some studies mention that this design could improve the indoor air quality and air change rate for cooling, especially in tropical regions [7]. However, this design has not been used for natural smoke extraction for buildings. This study will use Fire Dynamics Simulator (FDS) simulation software to analyze effective smoke removal from buildings on fire experiencing a strong ambient wind.

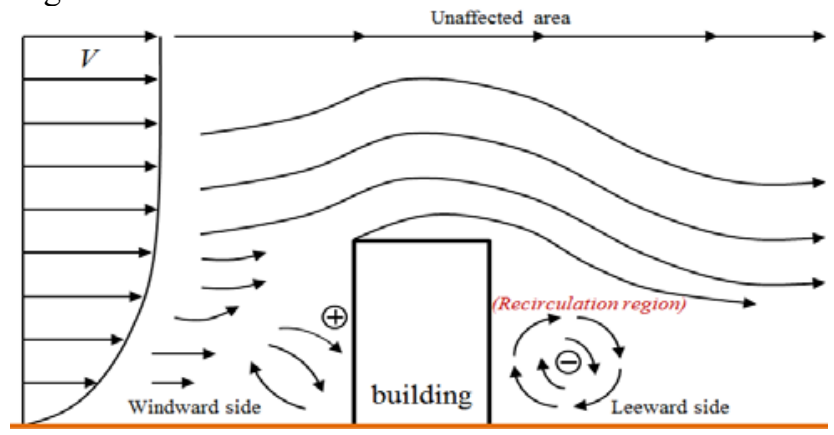

Figure 1. The impact of natural wind to buildings

\section{Research method}

\subsection{Venturi principle}

According to Bernoulli's law of fluid dynamics, static pressure decreases as the fluid velocity increases. Therefore, the velocity, increased through a reduced section of the fluid with any gain in kinetic energy, may be balanced by a pressure drop, as shown in Figure 2.

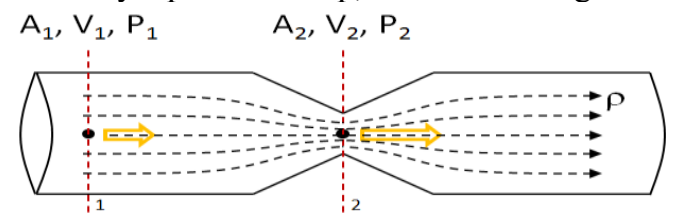

Figure 2. Venturi principle

Continuation equation $\quad Q=U_{1} A_{1}=U_{2} A_{1}$

Bernoulli equation

$$
\begin{aligned}
& \frac{p_{1}}{\gamma}+\frac{U_{1}^{2}}{2 g}=\frac{p_{2}}{\gamma}+\frac{U_{2}^{2}}{2 g}+\Delta Z_{2} \\
& \frac{p_{1}-p_{2}}{\gamma}-\Delta Z_{2}=\frac{1}{2 g}\left(U_{2}^{2}-U_{1}^{2}\right)
\end{aligned}
$$


The Venturi tube principle has been used in many experimental apparatuses for fluid. When the fluid flows through the flaring zone and throat zone in different sections of the Venturi tube, the different flow rates result in pressure differences [8].

The Venturi tube can be used to measure the fluid's flow rate. In engineering applications, a lot of equipment is set by using the Venturi principle, such as the foam mixing device for fire-fighting equipment. B. Blocken, T. van Hoff, et al. used the CFD and wind-tunnel experiment to research the effect of the different numbers of baffles on Venturi tube-shaped roofs of the same size [9].

\subsection{Introduction to FDS software}

This study used computer simulation software to build a fire simulation analysis, which is an extensively used method. The velocity, pressure, temperature and concentration represented by the grids of the fire location can be forecast accurately by the governing equation. The Field Model can simulate the actual conditions accurately, and this model is the one used most for simulation at present.

The FDS grid design must pay attention to both the efficiency and accuracy of the simulation. These two items are the main considerations in the simulation process. For the evaluation of an optimum grid, a fire source characteristic diameter computing mode is used to analyze the optimum grid size at the maximum heat release rate. McCaffery proposed the use of a minimum length scale for the fire plume as the characteristic fire diameter $\mathrm{D} *$ to determine the grid size [10]:

$$
D^{*}=\left[\frac{\dot{Q}}{\rho_{\infty} C_{\infty} T_{\infty} \sqrt{g}}\right]^{2 / 5}
$$

Herein:

$$
\begin{array}{cc}
\dot{Q}: \text { total heat release rate, } & \rho_{\infty}: \text { air density, } \mathrm{kg} / \mathrm{m} 3 \\
\mathrm{~kW} & T_{\infty}: \text { space temperature, } \mathrm{K} \\
\mathrm{g}: \text { gravitational } & C_{\infty}: \text { air's specific heat, } \\
\text { acceleration, } \mathrm{m} / \mathrm{sec} 2 & \mathrm{~kJ} / \mathrm{kg}-\mathrm{K}
\end{array}
$$

When the model set grid size is about one-tenth that of the characteristic diameter ( $\left.D^{*}\right)$, the LES simulated time average axis velocity and temperature match McCaffery's experimental regression equation.

\subsection{Wind scale}

In 1926, the Beaufort wind scale was used to describe the effect of the natural wind speed on land and sea surfaces. The Taiwan Weather Bureau uses this standard at present, shown in Table 1 [11].

Table 1. Beaufort wind scale

\begin{tabular}{|c|l|c|l|}
\hline Beaufort No. & Description & Wind speed $(\mathbf{m} / \mathbf{s})$ & \multicolumn{1}{c|}{ Land conditions } \\
\hline 0 & Calm & $<0.3$ & Calm. Smoke rises vertically. \\
\hline 1 & Light air & $0.3-1.5$ & $\begin{array}{l}\text { Smoke drift indicates wind direction. Leaves } \\
\text { and wind vanes are stationary. }\end{array}$ \\
\hline 2 & Light breeze & $1.5-3.3$ & $\begin{array}{l}\text { Wind felt on exposed skin. Leaves rustle. Wind } \\
\text { vanes begin to move. }\end{array}$ \\
\hline 3 & Gentle breeze & $3.3-5.5$ & $\begin{array}{l}\text { Leaves and small twigs constantly moving, } \\
\text { light flags extended. }\end{array}$ \\
\hline
\end{tabular}

\section{Fire scenario settings}


In Taiwan, building fire safety equipment is installed according to the "Standard for Installation of Fire Safety Equipment Based on Use and Occupancy" [12]. The opening area of the smoke vent must be larger than $2 \%$ of the smoke compartment. The smoke must be discharged naturally.

This study simulates discharging the smoke by natural smoke extraction from a high-rise building on fire in a free flow field. The heat release rate of the fire source is $1 \mathrm{MW}$. The building size is 10 $\mathrm{m}(\mathrm{H}) \times 8 \mathrm{~m}(\mathrm{~L}) \times 8 \mathrm{~m}(\mathrm{~W})$, and the door size is $2 \mathrm{~m}(\mathrm{H}) \times 2 \mathrm{~m}(\mathrm{~W})$, as shown in Figure 3. There are three vent window patterns, including:

Smoke vent on sidewall of building: According to regulations, the smoke vent is located $80 \mathrm{~cm}$ below the roof on the side of the building. The smoke vent area is $2 \%$ of the floor area.

Smoke vent at the top of building: The smoke vent is located at the top of the building. The opening area is $2 \%$ of the floor area.

Venturi-shaped roof on the building: The roof is located at the top. The area is $2 \%$ of the floor area. The smoke vent is located at the throat, and the throat height is $0.5 \mathrm{~m}$ [9].
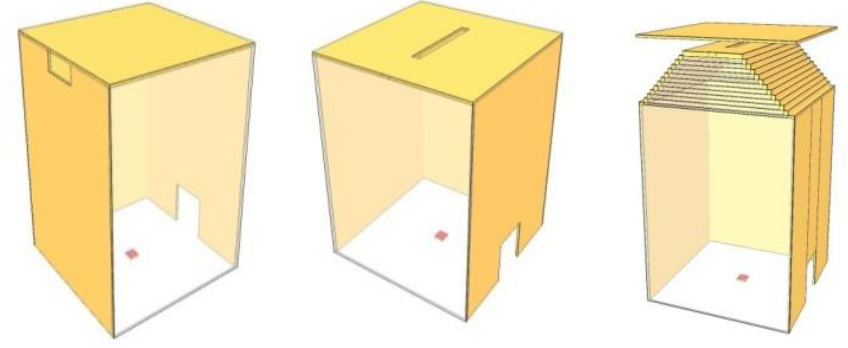

Figure 3. Exterior appearances of the simulation models

1. Space description: $48 \mathrm{~m}(\mathrm{~L}) \times 40 \mathrm{~m}(\mathrm{~W}) \times 45 \mathrm{~m}(\mathrm{H}), 19$ million cells.

2. Combustion regime: the fire source begins to burn when the air flow is stable after 30 seconds of simulation. The fire behavior is maximized immediately.

3. Fire source: the heat release rate is $1,000 \mathrm{~kW}$ in a fixed range. The maximum heat release rate is reached immediately. The chemical reaction of the fuel is the program's predetermined polyurethane.

4. Simulation time: 270 seconds.

5. Recorded items: three smoke vents are simulated under the natural ventilation effect. A flow rate variation of the smoke discharged from the smoke vent is observed. The pressure, temperature and flow rate at the monitoring points are recorded.

The fire scene simulation parameters are compiled in Table 2.

Table 2. The parameters of FDS simulation

\begin{tabular}{|c|c|c|}
\hline Heat release rate(kW) & $0.1 \mathrm{D} *(\mathrm{~m})$ & Grid size(m) \\
\hline 1,000 & 0.096 & 0.1 \\
\hline Zone & $\begin{array}{c}\text { Model Size } \\
\mathrm{L}(\mathrm{m}) \mathrm{xW}(\mathrm{m}) \times \mathrm{H}(\mathrm{m})\end{array}$ & $\begin{array}{l}\text { Grid size } \\
(\mathrm{m})\end{array}$ \\
\hline Entire space & $48 \times 40 \times 45$ & \multirow{6}{*}{$0.1 \times 0.1 \times 0.1$} \\
\hline Zone \#1 & $10 \times 10 \times 45$ & \\
\hline Zone \#2 & $11 \times 10 \times 45$ & \\
\hline Zone \#3 & $15 \times 10 \times 45$ & \\
\hline Zone \#4 & $9 \times 10 \times 45$ & \\
\hline Zone \#5 & $5 \times 10 \times 45$ & \\
\hline Zone \#6, \#7 & $48 \times 6 \times 45$ & $0.2 \times 0.2 \times 0.2$ \\
\hline Zone $\# 8, \# 9$ & $48 \times 9 \times 45$ & $0.6 \times 0.6 \times 0.6$ \\
\hline
\end{tabular}

\section{Results and discussion}




\subsection{Preliminary test}

The parameter setting conditions are imported into the executable file before simulation. The FDS is used for a 270 second simulation. The boundary condition of the natural wind velocity is Scale II of the Beaufort wind force scale, set as a mean of $2.4 \mathrm{~m} / \mathrm{s}$. In order to display the variation curve of natural wind from the ground to the upper space, the boundary is divided into 15 regions.

Equation $u=u_{r e f}\left(z / z_{r e f}\right)^{\mathrm{p}}$ is used, where $\mathrm{u}$ is the average wind speed at height $\mathrm{z} ; u_{\text {ref }}$ is the free flow field wind speed at height $z_{\text {ref }}$ and $\mathrm{p}$ is the Hellman exponent. The wind speed decreases by degrees in each region, and the wind speed at the height of the building's roof is set at $2.4 \mathrm{~m} / \mathrm{s}$ to simulate the pattern of the wind velocity gradient curve, from 4.24 to $1.10 \mathrm{~m} / \mathrm{s}$.

\subsection{Smoke vent on side wall of building}

A smoke vent is located on the wall within $80 \mathrm{~cm}$ below the building roof. The opening is $2 \%$ of the floor area. The fire source begins to burn when a steady state is reached after 30 seconds of simulation. Under the effect of buoyancy and makeup air inside the building, the fume flows upward. Under the effect of an external wind, the windward smoke vent has resistance; the smoke cannot be discharged through the smoke vent at the beginning, as shown in Figure 4 (A). The dense smoke accumulates downward under the ceiling.

The sustained combustion increases the smoke accumulated under the ceiling and the hot air driving force in the building. The smoke is discharged through the smoke vent. Figure 4 (B) shows the smoke extraction velocity profile at $240 \mathrm{sec}$. The outward air flow velocity at the smoke vent is 4.22 $\mathrm{m} / \mathrm{s}$. The outside smoke flow rate is increased by the natural wind. There is still resistance generated by the external natural wind at the smoke vent, extruding into the building. The smoke extraction effect is obviously inhibited.

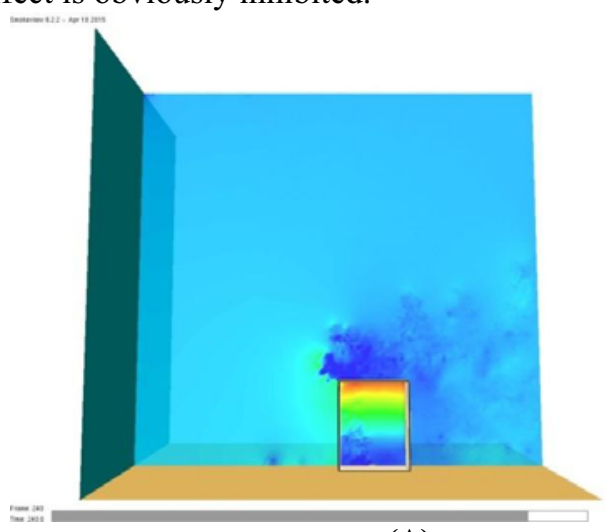

(A)

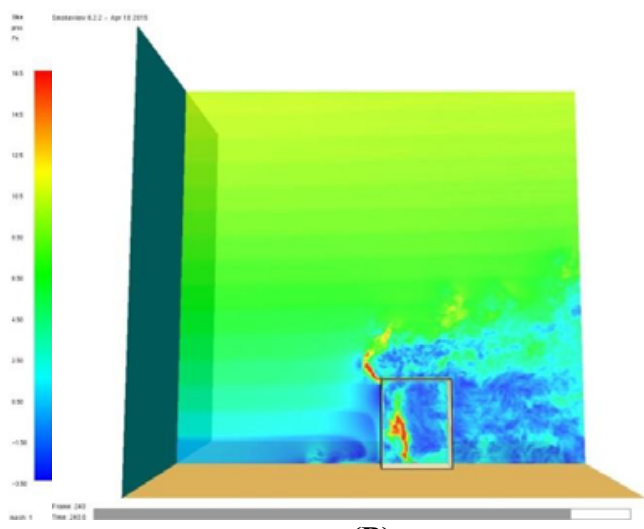

(B)
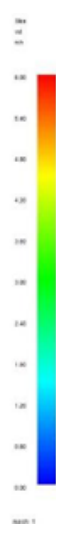

Figure 4(A). Pressure distribution of smoke vent on sidewall(@240 second) (B). Velocity distribution of smoke vent on sidewall(@240 second)

\subsection{Smoke vent on top of building}

The air flow is in a steady state after 30 seconds of simulation. A negative pressure zone is formed externally above the building. The smoke vent is located in this region. The smoke flows up to the upper space rapidly under the thermal buoyancy. Figures 5 (A) and (B) show that at the initial stage, there is a negative pressure zone outside above the building. The high pressure in the building is released towards the smoke vent. There is a low pressure of $1.16 \mathrm{~Pa}$ outside above the building at 240 $\mathrm{sec}$, forming a pressure difference from the internal high pressure, so that a $5.74 \mathrm{~m} / \mathrm{s}$ high-velocity air blast is created, discharging the smoke and hot air from the building. As there is a negative pressure 
zone outside the smoke vent in this case, the smoke accumulates in the building slowly. The upper smoke vent has a good smoke extraction effect, but it needs improvement because when it rains, water or foreign materials enter the building.

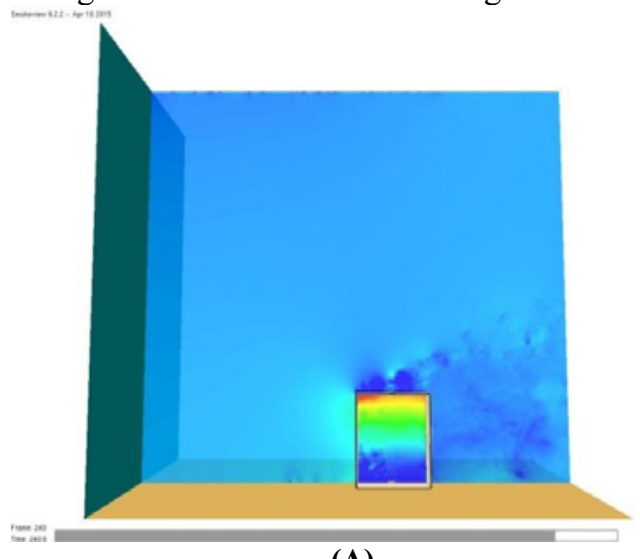

(A)

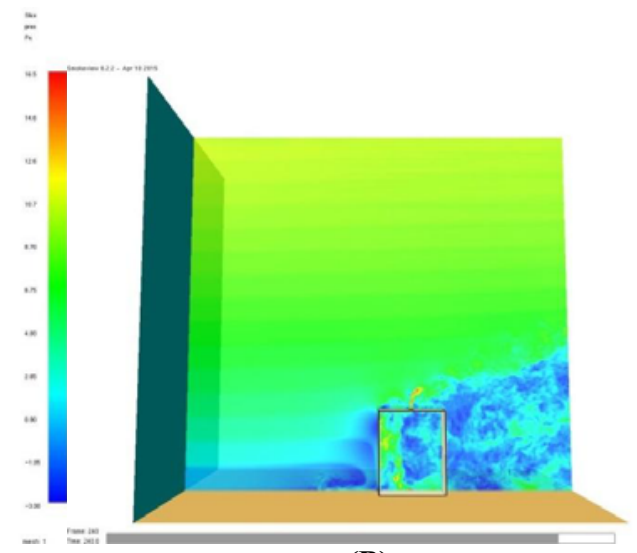

(B)

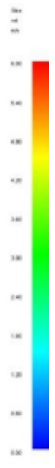

Figure 5(A). Pressure distribution of upper smoke vent(@240 second) (B). Velocity distribution of upper smoke vent(@240 second)

\subsection{Buildings with a Venturi-shaped roof}

The Venturi-shaped roof is used for improvement in this study. The Venturi-shaped roof uses the Venturi principle to enhance smoke extraction. When the air flow is stable at $30 \mathrm{sec}$, a negative pressure zone is formed at the throat of the smoke vent. When the static pressure decreases, the dynamic pressure increases, resulting in a high flow velocity. At $66 \mathrm{sec}$ of simulation, the maximum negative pressure $6.94 \mathrm{~Pa}$ is formed in the throat zone.

Figures 6 (A) and (B) show that the wind pressure resistance on the windward side generates a natural wind through the throat zone to form negative pressure due to its special design. The pressure increases gradually with the height inside the building to $240 \mathrm{sec}$. The high-pressure smoke flows towards the throat's negative pressure zone, discharging the smoke rapidly. The smoke is blown away from the building by the air flow at the throat.

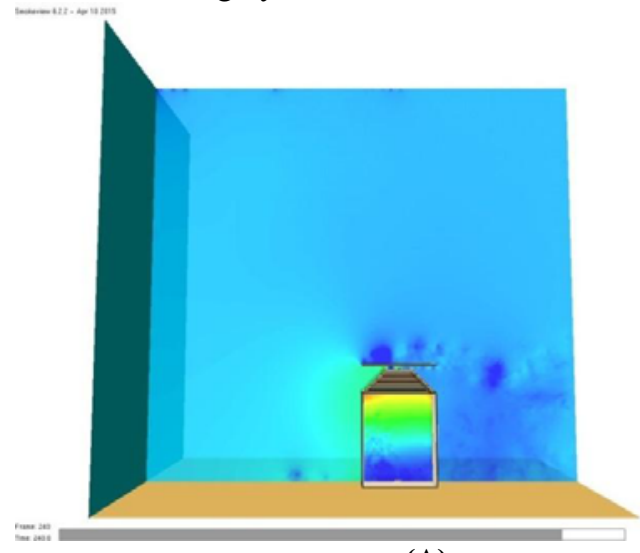

(A)

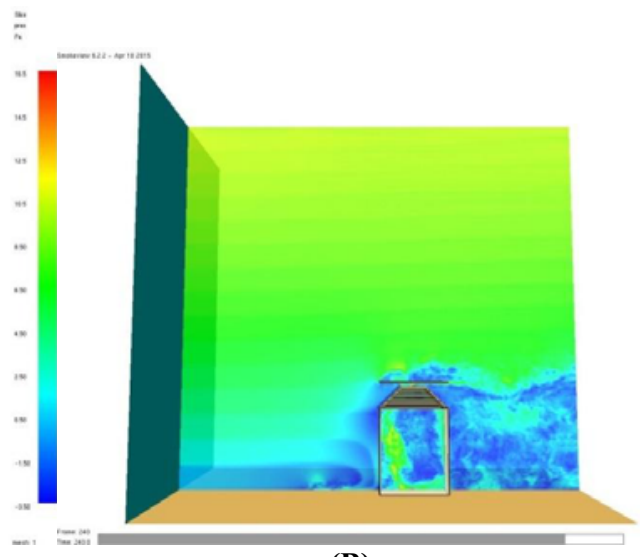

(B)

Figure 6(A). Venturi-shaped roof pressure distribution(@240 second) (B). Venturi-shaped roof velocity distribution(@240 second) 
Figure 7 shows that some air is exhausted through the smoke vent at the steady stage of air flow, especially for the side smoke vent. When the fire begins to burn, the flow rate at the smoke vents at the top of the building and the Venturi-shaped roof increase rapidly; the $5.6 \mathrm{~m} / \mathrm{s}$ extraction velocity is implemented immediately.

Figure 8 indicates the temperature of the smoke at the smoke vent. It is observed that the temperature rises gradually at the initial stage of smoke extraction. The smoke vents at the top of the building and the Venturi-shaped roof discharge smoke immediately when the smoke is formed. Smoke extraction through the side smoke vent is delayed. The curve jitter in the red circle of Figure 8 represents an eddy formed in the building, so that the discharged smoke volume and the temperature decrease. The temperature at the outlet increases with the exhaust's smoke level. The temperature at the side smoke vent is higher than the other two patterns as the air flow is relatively slow when the smoke extraction is stable.

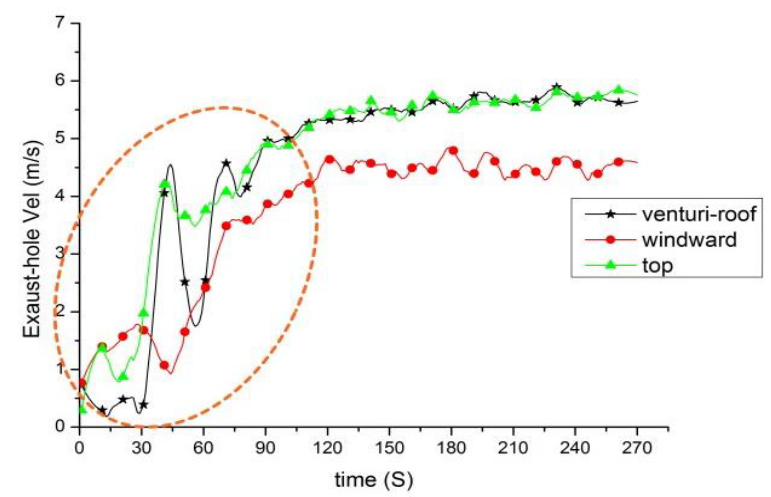

Figure 7. Velocity curves of three smoke vents

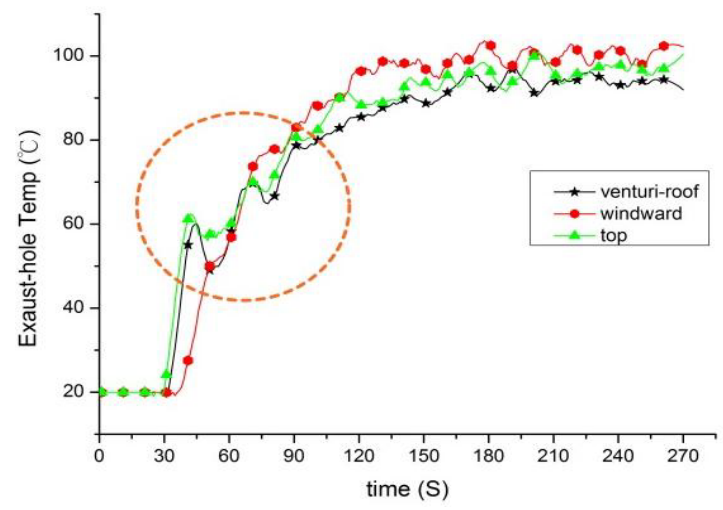

Figure 8. Temperature curves of three smoke vents

\section{Conclusion}

Fires cause more casualties in buildings with increased height. The effectiveness of building fire equipment has been studied a lot. Fire simulation software FDS is used in this paper to analyze the pressure, temperature, velocity and plume flow at the scene of a fire. The building is provided with three scenarios for smoke vents to evaluate the effectiveness of smoke extraction. The analysis's results show that when the smoke vent is located on the side, the smoke is slowly discharged through the smoke vent under the effect of the windward side; the smoke is likely to accumulate, resulting in high internal temperatures. If a negative pressure zone is formed outside the smoke vent, smoke extraction can obviously be improved. 


\section{Acknowledgement}

The authors gratefully acknowledge the financial support from the Ministry of Science and Technology under Grant no. NSC 102-2221-E-274-001-MY3.

\section{References}

1. DiNenno, P. J. SFPE handbook of fire protection engineering (SFPE,2008)

2. Su, C. H., Tsai, K. C. and Xu, M. Y. Journal of Building Performance Simulation. Computational analysis on the performance of smoke exhaust systems in small vestibules of high-rise buildings, 8(4), 239-252 (2015)

3. Kobes, M., Helsloot, I., de Vries, B. and Post, J. G. Fire Safety Journal. Building safety and human behaviour in fire: A literature review , 45(1), 1-11 (2010)

4. National Fire Protection Association, NFPA 921: Guide for Fire and Explosion Investigations. Chapter 3: Definitions, pp.18 (2014)

5. W. Conshohocken. ASTM International, ASTM E176-04 Standard Terminology of Fire Standards, (2004)

6. Yamana, T. and Tanaka, T. Fire Science and Technology. Smoke control in large scale spaces, 5(1), $41-54$ (1985)

7. van Hooff, T., Blocken, B., Aanen, L. and Bronsema, B. Building and Environment. A venturishaped roof for wind-induced natural ventilation of buildings: wind tunnel and CFD evaluation of different design configurations ,46(9), 1797-1807 (2011)

8. Spoerel, W. E., Narayanan, P. S. and Singh, N. P. British journal of anaesthesia. Transtracheal ventilation, 43(10), 932-939 (1971)

9. Blocken, B., van Hooff, T., Aanen, L. and Bronsema, B. Computers and Fluids. Computational analysis of the performance of a venturi-shaped roof for natural ventilation: venturi-effect versus wind-blocking effect, 48(1), 202-213 (2011)

10. Baum, H. R. and McCaffrey, B. J. Fire Safety Science. Fire induced flow field-theory and experiment, 2, 129-148 (1989)

11. Wheeler, D. and Wilkinson, C. The Mariner's Mirror. From calm to storm: the origins of the Beaufort wind scale, 90(2), 187-201 (2004)

12. National Fire Agency. Standard for Installation of Fire Safety Equipments Based on Use and Occupancy. Ministry of the Interior, Taiwan (2012) 